\title{
Ergonomic analysis of the use of open-plan offices in Brazilian public sector offices
}

\author{
Ana Paula Lima Costa ${ }^{\mathrm{a}}$, Vilma Villarouco ${ }^{\mathrm{b}}$ \\ a Master Design, UFPE, aplimacosta@gmail.com, PE, Brazil \\ ${ }^{\mathrm{b}}$ Doctor Production Engineering, Post graduate Program on Design, UFPE, villarouco@hotmail.com, PE, Brazil
}

\begin{abstract}
The open-plan office is a layout used in government offices in Brazil aimed at saving on space occupied and integrating employees. However, the design of these work-stations must follow the characteristics of tasks and their interrelationships, since adverse physical and organizational conditions may have a negative impact on work productivity. From this perspective, this study sought to identify, from the viewpoint of the ergonomics of the built environment, the adequacy of the open-plan government offices for financial auditing accounts and analyzing documents. Use was made of the Ergonomic Methodology for Evaluating the Built Environment - MEAC (in Portuguese) which systematically analyzes the physical space, by using a mix of physical-spatial assessments and tools for identifying how the environment is perceived. The MEAC was employed in three analytical phases of the physical aspects, namely: an analytical phase of the user's perception; a diagnostic phase; and a final phase of propositions.
\end{abstract}

Keywords: built environment; organizational culture; environmental perception

\section{Introduction}

The open-plan layout is a form of office occupation that was developed to promote interrelationships within an organization [2]. This layout, first thought of as adjusting the physical environment to the organizational culture of an enterprise, was adopted in Brazilian government offices with a view to reducing the financial costs of occupying physical space. However, in recent years, the adoption of open-plan offices has been questioned because of the high rate of complaints from users of the space. Bearing in mind that, in order to propose a model of physical occupation, the behavioral attitudes, the work and the tasks to be performed should be identified, it is important to take into consideration the needs of those who will use the environment.

According to Sommer [8], when conditions are unfavorable, the individual works harder so as to compensate for his/her difficulties. Bearing in mind that administrative models and philosophies seek to set management paradigms and modify the attitudes and behavior of members of the organization [1], consid- eration should always be given to the people who use the environment and the work they do.

The work environment should not only be adapted to the structural and cultural requirements of the organization, but also the employees' needs. [3]. A pleasant environment, with facilities that satisfy its users, has been shown to be important for the job. According to Gifford [6], satisfying the users of the building is important because the occupants spend significant parts of their lives in it. The work environment should translate the needs and activities of its occupants, by ensuring it is inhabitable and that its appointments can, according to the author, increase staff productivity in offices and improve the social bonds between people.

According to Bins Ely [4], in a work environment, environmental aspects, the spatial concept of the environments, and the environmental layout and comfort are also important tools for improving conditions for performing work, in addition to organizational aspects, such as human resources and norms of work organization. Given that users' functional needs are directly related to the requirements of the task, in order that the environment may meet these require- 
ments, consideration must be given to the size and shape of the space, equipment and furnishings, the circulation flows and arrangement of the furniture and also to thermal, lighting and sound comfort.

Gots [7] states that some symptoms that workers may associate with the environment are of different natures, it being necessary to determine one diagnosis for the worker and another for the building, and thereafter to integrate the two, which involves multidisciplinary considerations.

\section{Method}

With a view to identifying variables in the environment of open-plan offices that facilitate or inhibit the performance of activities, three work spaces in public departments were analyzed. These departments have standardized their environments by using open-plan layouts, with no thought having been given to the activities to be performed in them, thus ignoring the precepts of the adaptability and compliance of the space to the activities.

The studies were conducted in line with the approach of the Ergonomic Methodology for the Evaluation of the Built Environment - MEAC, in Portuguese [9], which analyzes the physical space under the focus of ergonomics. In this methodology, Villarouco [10] suggests that the built environment be evaluated guided by a systemic approach, covering variables of the areas involved in the builtspace. As it is an ergonomic analysis, the project regards the primary element as being the users of this space and their environmental perceptions, because they are the elements that absorb the impacts that the environment provokes.

This methodology aggregates physical evaluations of the space to environmental perception tools, and is divided into the following steps:

- Analysis of the physical aspects: Global analysis of the environment, Identification of the environmental configuration and Evaluation of the environment in use when activities are performed.

- Analysis of the subjective aspects: Analysis of the user's perception

- Ergonomic diagnosis

- Ergonomic propositions

\section{Results}

This study selected three public departments that had work rooms with an open-plan layout, deemed offices A, B and C. In these work rooms, activities are carried out in which occurrences of interference external to the work affect the performance of daily tasks in terms of productivity.

Given the similarity of the three work environments, this article presents the results of the ergonomic analyses together.

\subsection{Global analysis of the environment}

The global analysis of the environment includes the initial step of the evaluation phase of the physical aspects of the environment. In this stage of the analysis, the description of the production unit is made and the initial perceptions of the researcher are collected.

All three offices are located in buildings shared with other public institutions.

The work rooms of office A (Figure 1) and office $\mathrm{B}$ (Figure 2) are located in a federal government agency which provides services in auditing accounts in public companies.

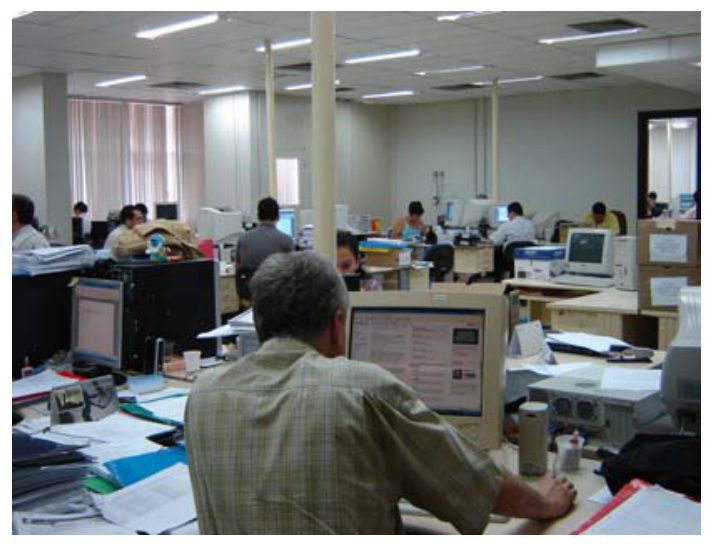

Figure 1- The work room of office A 


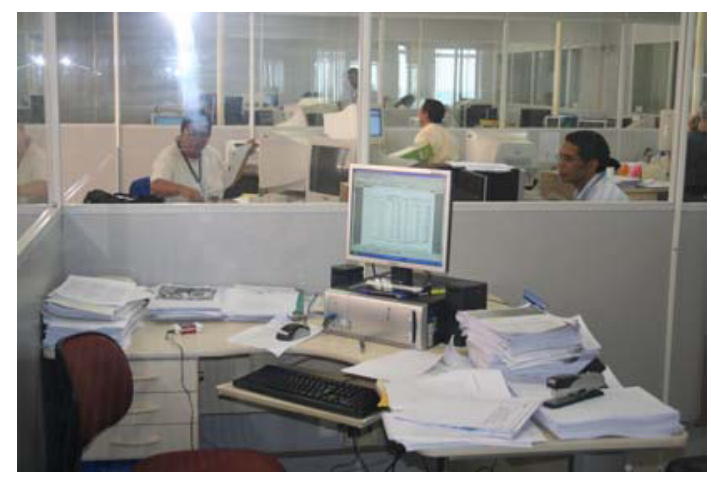

Figure 2- The work room of office B

The work room of office $\mathrm{C}$ (Figure 3 ) is located in a state government agency in which the services of preparing the payroll are carried out.

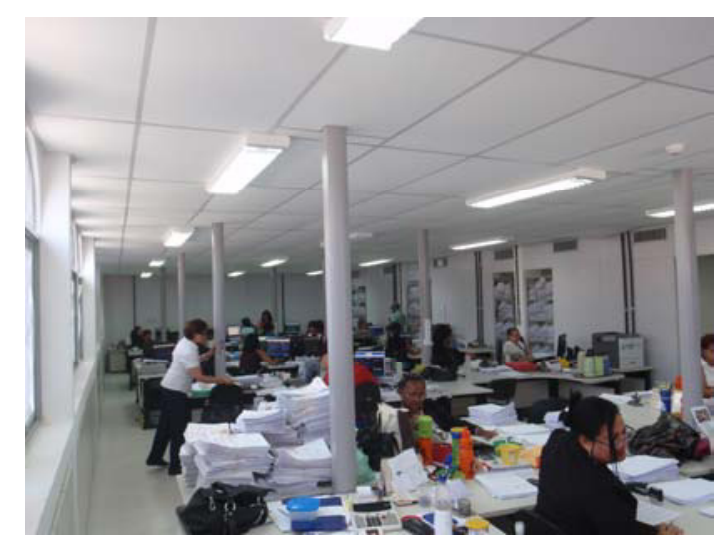

Figure 3- The work room of office $\mathrm{C}$

\subsubsection{Initial perception of the observer}

The lack of space to store objects was shown to be the biggest factor that causes the initial poor impression of the environment, as can be seen in office A, Figure 4.

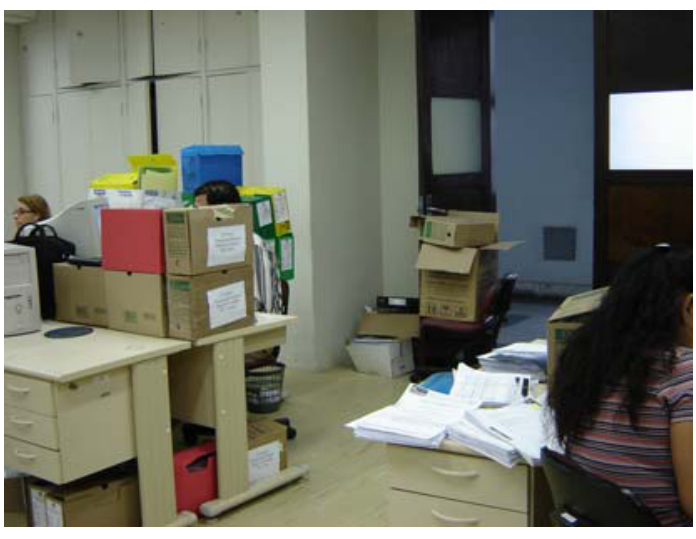

Figure 4- The lack of space of office A

In the three environments, people move about and talk all the time, in contrast to an environment of retreat which the activities require (Figure 5). There are no restrictions on external public access to the interior of the offices. There are no visual cues as to the internal divisions of departments or posts held by team leaders.

In office $\mathrm{A}$, the physical sensation perceived is one heat and noise; in office $B$ one perceives that the environment has irregular lighting; and in office $\mathrm{C}$, one notes a high level of noise in the environment caused by the users of the office.

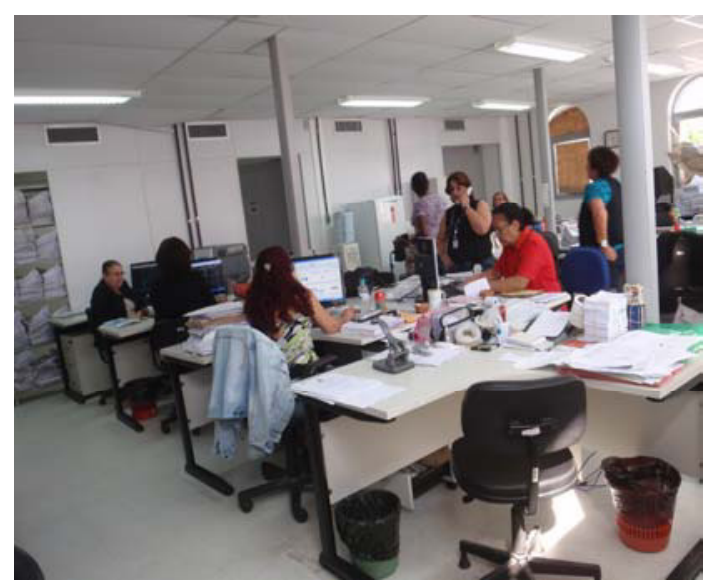

Figure 5- View of the people in the office C

\subsection{Identifying the environmental configuration}

The second step of the evaluation phase of the physical aspects of the environment is to identify the Environmental Configuration. This step identifies the physical and environmental conditioning factors by 
making a survey of the environmental data, and thus analyzing the influences of the conduct of work activities. An analysis is made of space in the layout, the circulation flow, the levels of environmental comfort and work stations.

\subsubsection{Layout}

In offices $\mathrm{A}, \mathrm{B}$ and $\mathrm{C}$, the use of an open-plan layout is identified, as shown in the sketches of the floor plans in Figure 6. The open space was used to integrate the work teams and to save physical space on occupying the office. However, what were not considered were the implications arising from the use of open space, such as integration between work teams which can adversely affect users' concentration and, consequently, their production. The lack of zoning the activities in the environment causes the functions of the spaces to overlap.

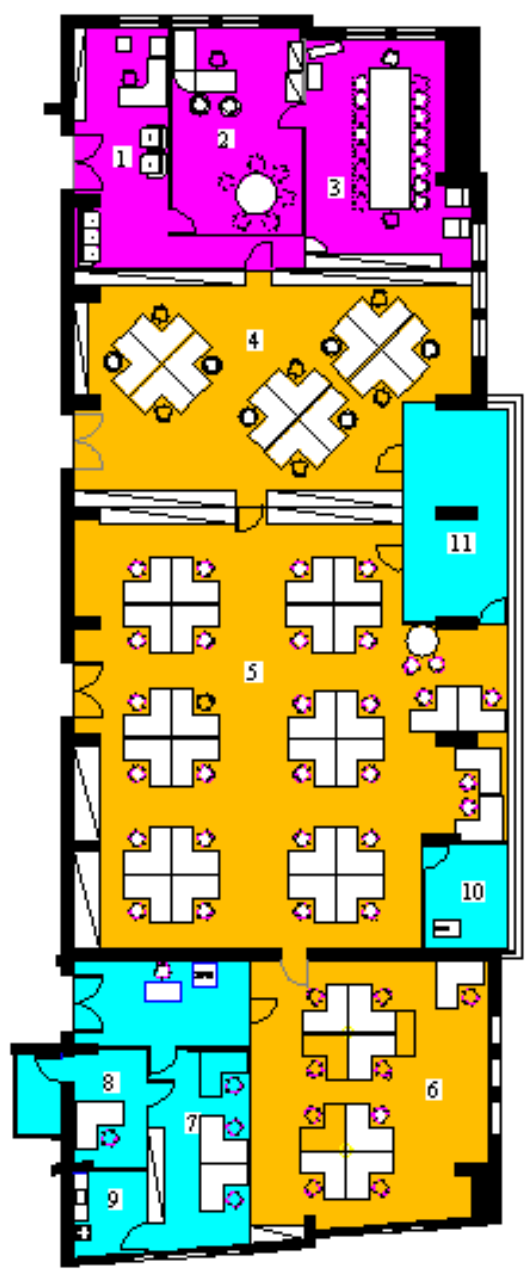

Office A

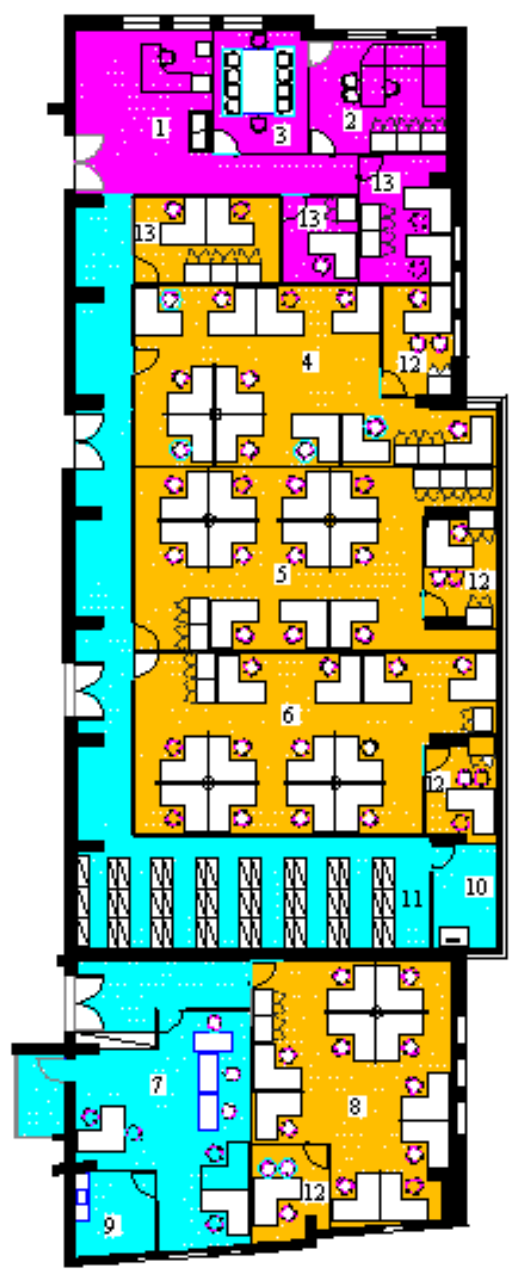

Office B
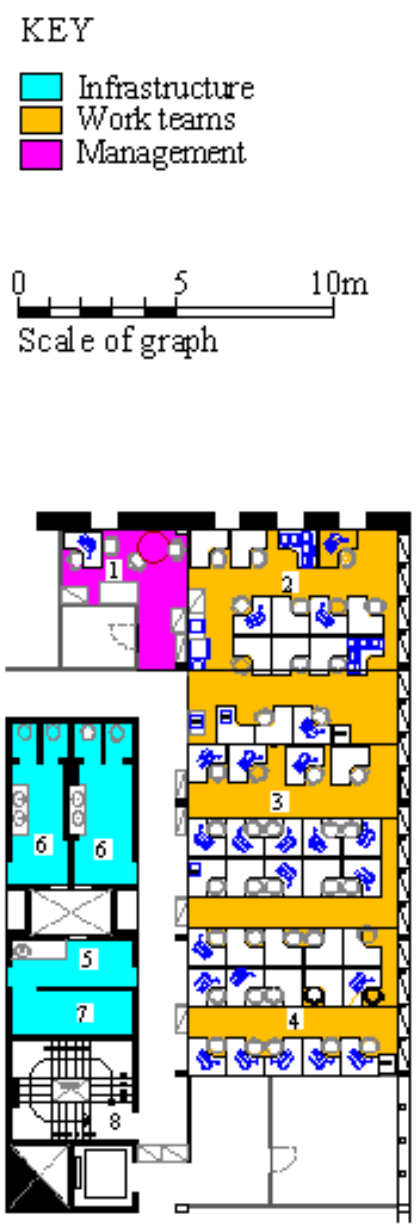

Office C

Figure 6- Floor plan of the office A, office B and office C 


\subsubsection{Circuklation flow}

The lack of zoning the activities in offices A, B and $\mathrm{C}$ causes the flow of the people who circulate through the rooms to be close to the work stations, thus hampering the performance of services because this fact of movement close to work stations distracts the staff's attention. Thus, the circulation flow becomes a negative factor when sizing such circulation and is not compatible with the volume of to-ing and fro-ing.

\subsubsection{Workstations}

The furniture in offices $\mathrm{A}, \mathrm{B}$ and $\mathrm{C}$ was not dimensioned in accordance with the use and the activities undertaken by users, which causes problems in performing the tasks. The lack of partitions between work stations makes it possible to mix work material between the desks, and is evidence of the lack of privacy (Figure 7). There is no adequate space in the environment for storing material and personal objects. Although the users of the three environments have been given furniture recommended for open-plan spaces, they responded that they are dissatisfied with its usability. They claim that in the context of the environment, their basic needs for comfort are not met.

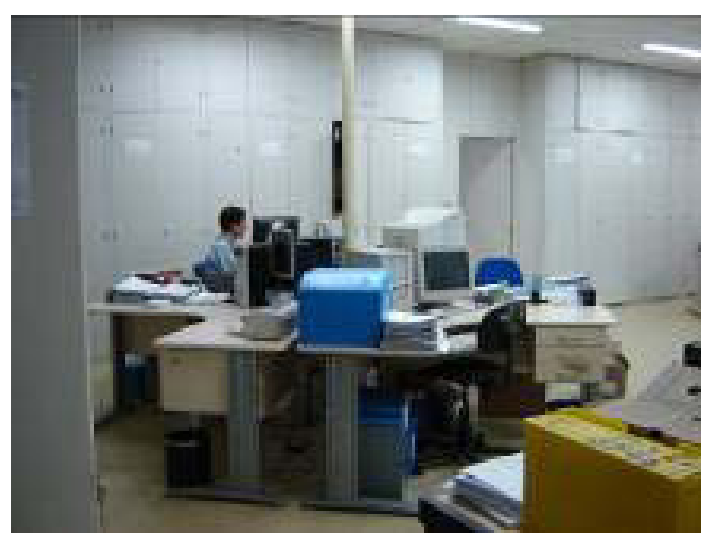

Figure 7- The work stations of the office A

\subsubsection{Indices of environmental comfort}

In offices $\mathrm{A}, \mathrm{B}$ and $\mathrm{C}$, the levels of lighting, noise and temperature were measured, and compared with the level of comfort determined by Brazilian technical norms.

- In offices A, B and C, the values measured of the levels of lighting varied greatly, there being dark areas and areas with incidence of solar radiation on work surfaces. The averages of luminance of the three offices were below the lighting indices set by the norms, resulting in areas that were poorly lit. However, the poor distribution of the lighting of the environments is not perceived by the users.

- In offices $\mathrm{A}, \mathrm{B}$ and $\mathrm{C}$, the temperature values measured were above the limits of comfort recommended by Brazilian norms. The high temperature is a target of complaints of discomfort by the users of the site.

- Also the values measured of noise in the environment were above the maximum limit set as comfortable by the norms. This is a cause of discomfort to users who request to stay in smaller rooms according to the work groups. This would also reduce the number of people in one place and thus reduce environment noise.

\subsection{Evaluation of the environment in use in carrying out activities}

This stage of the evaluation aims to identify its usability, i.e. the extent to which it represents facilitating or inhibiting the conduct of the activities which it houses.

The use of the open-plan office without complying with its basic premises of providing individual spaces, and without having dimensions compatible with the number of people who use it, causes discomfort. The high circulation close to desks is the main factor in the inadequate use of this layout. Due to the cramped physical space, clutter causes interference between the various zones of activities and functions of the spaces.

\subsection{Analysis of the user's perception}

This phase of the ergonomic analysis of the built environment consists of identifying variables of a more cognitive, and perceptual, character, evaluated by the Constellation of Attributes [5]. The symbolic images and the perceptions on the work environment of those who use them are observed.

In the evaluation phase of the symbolic image of the individual vis-à-vis the environment, the characterization of an imaginary environment is asked for, which causes users to relate to the attributes that they long for in their workplace. In the evaluation phase of the perception of the individual vis-à-vis the environment, he/she is 
requested to identify the characteristics of the environment he/she uses, thus describing the environment used. In order to distinguish between what is objective from that which is subjective in the user's perception, the users' subjective impressions of the direct impressions are brought face-to-face. These data are complemented with the data obtained in the measurements and evaluations of the environment.

The examples of an imaginary environment given by the users of offices $\mathrm{A}, \mathrm{B}$ and $\mathrm{C}$ referred to a pleasant, comfortable and spacious environment. When they talked about the environment that they used, the users first cited the negative aspects, thus reflecting the discomfort they felt in the workplace.

When comparing the subjective impressions with the direct impressions of the users on the environment, the discomfort that the users felt in the workplace is identified, thereby complementing the data presented in the physical measurements and evaluations of the environment.

\subsection{Ergonomic diagnosis and propositions}

The ergonomic diagnosis of the ergonomic analysis of the environment combines the data of physical analysis and the analysis of users' perceptions. This gives evidence of flaws regarding the match between the work spaces of the offices and the work procedures drawn up by the departments.

\subsubsection{Layout}

a). Diagnosis: In offices A, B and C spaces do not have dimensions that can comfortably accommodate users and their furniture. There is a lack of facilities and equipment to facilitate the movement of people with physical limitations.

b) Propositions: in offices A, B and C, spaces should be reworked to accommodate users such that they may have comfort, security and privacy when carrying out their tasks.

\subsubsection{Circulation flows}

a) Diagnosis: In offices A, B and C, the lack of zoning for activities creates a flow of people close to the work station.

b) Propositions: In offices $\mathrm{A}, \mathrm{B}$ and $\mathrm{C}$, the zoning of activities should be introduced in order to avoid a heavy flow of people close to work stations.

\subsubsection{Work stations}

a) Diagnosis: In offices A, B and C, the work stations are not adequately dimensioned for the performance of the activity, nor do they have enough space for users to move in.

b) Propositions: In offices A, B and C, the work stations must be designed based on an ergonomic analysis of the activity.

\subsubsection{Measurements}

a) Diagnosis: In offices A, B and C, the loud background noise in the environments is detrimental to the conduct of the activity. The high temperature causes discomfort and the average luminosity is below the recommended level of illuminance.

b) Propositions: In offices $\mathrm{A}, \mathrm{B}$ and $\mathrm{C}$, acoustic adjustments should be made to eliminate excessive noise so as to match noise to the conditions of environmental comfort; changes in the air conditioning system to match it to the conditions of comfort and adjustments in the lighting system to provide illuminance appropriate for the conduct of activities.

\subsubsection{Spaces for moving around in}

a) Diagnosis: In offices A, B and C, the spaces are large enough for the movement of users. However there are circulation flows next to the work stations.

b) Propositions: In offices A, B and C, zoning for activities should be introduced in order to avoid the heavy flow of people close to the work stations.

\subsubsection{Analysis of the user's perception}

Users' main aspirations are related to issues of material resources, the facilities of the building and environmental comfort. The perceptions of the real environment give evidence that the open-plan space is used inadequately.

\subsubsection{Ergonomic diagnosis and general propositions for the environments}

It was found that the physical spaces were considered unsatisfactory for accommodating the users such that they perform their tasks comfortably and safely. Thus, the use of the open-plan layout was shown to be ergonomically inadequate, when adopted in places that require concentration and isolation to perform tasks. 
The open-plan office was used in the government offices studied because it economized on floor space in relation to occupation in individual rooms. However, this layout was adopted without observing either the work relationships of its users, or the physical conditions of the environment necessary to house a large amount of people in a single room. Nor was the furniture suitable for this type of occupation studied.

It is recommended that when setting up the openplan layout, approaches should be adopted based on scientific methods of ergonomics. They should include and integrate the physical, sensory and organizational factors to verify the adequacy of the space for the use desired so as to achieve the quality of the place.

The open-plan office was designed to encourage inter-relationships within a company, with the open space being used by workers of various hierarchical levels. Thus, this configuration should only be used by the company when this integration is desired, this thought being one which should be in accordance with the organizational culture, so as to promote communication between teams.

\section{Discussion}

The work environment will be more productive, the better the worker's health and work efficiency is ensured. According to Gifford [6], satisfying the users of built spaces is important because the occupants spend significant parts of their lives in work environments. The best use of the environment should be achieved by combining the needs and activities of its occupants. Such compliance may, according to the author, increase staff productivity in offices. This makes the decision to open or close the environment depend on the work stations, and the need to carry out tasks that require low interaction between workers and autonomy. The inadequacy of observing this factor sees to it that the spatial configuration of open-plan offices is not in accordance with the configuration of work, thus making them areas that are not suited to the activity.

The work environment should be adapted to the structural requirements of the organization and the needs of its collaborators [3]. Thus, it should also consider the size and format of the space, the circulation flow, the arrangement of furniture (layout), and thermal, light and sound comfort.

The evaluations carried out using MEAC gave evidence of flaws regarding the match between the work spaces of the offices and the work procedures conducted by the department. What is also explained are instances of dissatisfaction among staff in relation to the work, mainly caused by these spatial aspects. As a consequence of this disconnection, there is dissatisfaction among users with regard to the space.

\section{References}

[1] AIDAR, Marcelo Marinho; ALVES, Mário Aquino. Comunicação de massa nas organizações brasileiras. Explorando o uso de historias em quadrinhos, literatura de cordel e outros recursos populares de linguagem nas empresas brasileiras. In: MOTTA, Fernando Prestes; CALDAS, Miguel. Cultura Organizacional E Cultura Brasileira. São Paulo: Atlas, 1997

[2] AMARAL, Cláudio. Arquitetura revela filosofia de trabalho. Folha de São Paulo, São Paulo, p. C30, 8 nov.1987

[3] ASSELBERGS, F.; SCHREIBERS, K.; VAN DER VOORDT, J. M. Theo. Kantoren. In.: Arbo Jaarboek 2008, p. 333-346. Buitendam, A. Kluwer, 2008.

[4] BINS ELY, Vera Helena M. Ergonomia + Arquitetura: buscando um melhor desempenho do ambiente físico. In: Anais do $3^{\circ}$ ERGODESIGN Congresso Internacional de Ergonomia e Usabilidade de Interfaces Humano-Tecnologia: Produtos, Programas, Informação, Ambiente Construído, 2003

[5] EKAMBI-SCHMIDT, J., La percepción del hábitat (In Spanish),. Barcelona, Gustavo Gili, 1974.

[6] GIFFORD, Robert. O papel da Psicologia ambiental na formação da política ambiental e na construção do futuro. Psicologia USP, 16, p.237-247. 2005

[7] GOTS, Ronald E. Investigating health complaints. In: O'Reilly, J. T.; Hagan, P.; Gots, R.; Hedlge, A. Keeping buildings healthy: how to monitor and prevent indoor environmental problems. New York, 1998

[8] SOMMER, Robert. Persona space: the behavior basis to design and planning (In Portuguese), São Paulo: Ed. da Universidade de São Paulo.1973

[9] VILLAROUCO, Vilma. An ergonomic look at the work environment, In Proceedings of IEA 2009: 17th World Congress on Ergonomics. Beijing, China, IEA - International Ergonomics Association. 2009

[10] VILLAROUCO, Vilma. Construindo uma metodolo-gia de avaliação ergonômica do ambiente - AVEA. In: Anais do XV Congresso Brasileiro de Ergonomia - ABERGO- Porto Seguro, 